\title{
Meta-analysis of the surgical outcomes of symptomatic moyamoya disease in adults
}

\author{
Jin Pyeong Jeon, MD, ${ }^{1}$ Jeong Eun Kim, MD, ${ }^{2}$ Won-Sang Cho, MD, ${ }^{2}$ Jae Seung Bang, MD, ${ }^{2}$ \\ Young-Je Son, MD, ${ }^{2}$ and Chang Wan Oh, MD²

\begin{abstract}
1Department of Neurosurgery, Hallym University College of Medicine, Chuncheon; and 2Department of Neurosurgery, Seoul National University College of Medicine, Seoul, Korea
\end{abstract}

\begin{abstract}
OBJECTIVE The purpose of this study was to evaluate treatment outcomes of future stroke prevention, perioperative complications, and angiographic revascularization in adults with symptomatic moyamoya disease (MMD) according to treatment modalities and surgical techniques.
\end{abstract}

METHODS A systemic literature review was performed based on searches of the PubMed, Embase, and Cochrane Central databases. A fixed-effects model was used in cases of heterogeneity less than $50 \%$. Publication bias was determined by Begg's funnel plot, Egger's test of the intercept, and the Begg and Mazumdar rank correlation test.

RESULTS Eleven articles were included in the meta-analysis. Bypass surgery significantly decreased the future stroke events compared with conservative treatments in adult MMD (odds ratio [OR] 0.301, $p<0.001$ ). Direct bypass showed better future stroke prevention than indirect bypass (OR 0.494, $p=0.028)$. There was no meaningful difference in perioperative complications between direct and indirect bypass (OR $0.665, p=0.176)$. Direct bypass was associated with better angiographic outcomes than indirect bypass (OR 6.832, $p<0.001)$.

CONCLUSIONS Bypass surgery can be effective in preventing future stoke events in adults with MMD. Direct bypass seems to provide better risk reduction with respect to stroke than indirect bypass in these patients.

https://thejns.org/doi/abs/10.3171/2016.11.JNS161688

KEY WORDS moyamoya disease; postoperative; stroke; vascular disorders

$\mathrm{M}$ oyamoya disease (MMD) refers to an abnormal progressive steno-occlusive disorder of unknown etiologies at the distal internal carotid artery (ICA) or proximal middle cerebral artery (MCA) with abnormal collateral vessel formation. ${ }^{34}$ A current treatment concept is to prevent cerebral ischemia by augmenting cerebral blood flow in patients with an ischemic presentation and to prevent intracranial hemorrhage by decreasing hemodynamic stress in patients with a hemorrhagic presentation. ${ }^{18}$ MMD treatment outcomes have been increasingly published; but heterogeneity among studies with respect to such variables as treatment modalities, surgical techniques, and patient age as well as limited sample sizes could present concerns in interpreting the results. In particular, MMD prevalence shows a bimodal age pattern ${ }^{31}$ with different clinical manifestations and treatment policies; pediatric patients with MMD mainly present with ischemic symptoms. ${ }^{20,31}$ The efficacy of direct bypass is not significantly different from the efficacy of indirect bypass in the pediatric population. ${ }^{8}$ Adult
MMD patients experience more hemorrhagic stroke than pediatric MMD patients. ${ }^{31}$ Regarding treatment of adult MMD, no definite recommendation can be given, although surgical benefits of direct bypass have been increasingly reported., ${ }^{2,18,27}$ MMD shows approximately a 2:1 female predominance,,$^{31}$ although female predominance has been found to be more pronounced in Europe $(4.25: 1)^{21}$ and the US (5:1). ${ }^{10}$ Kleinloog et al. ${ }^{20}$ reported that the incidence of MMD was higher in Japan (0.35-0.94 per 100,000 patient-years) than in the US $(0.05-0.17$ per 100,000 patient-years). For adult patients, the frequency of hemorrhagic presentation is also higher in Asia than in the US..$^{18,21}$

We conducted a meta-analysis to evaluate treatment outcomes of future stroke events, perioperative complications, and angiographic revascularization in symptomatic adult patients with MMD according to treatment modalities (surgical revascularization vs conservative treatments) and surgical techniques (direct and combined bypass vs indirect bypass).

ABBREVIATIONS $\mathrm{Cl}=$ confidence interval; ICA = internal carotid artery; $\mathrm{MCA}=$ middle cerebral artery; MMD = moyamoya disease; NOS = Newcastle-Ottawa Scale; OR = odds ratio; TIA = transient ischemic attack.

SUBMITTED June 27,2016. ACCEPTED November 17, 2016.

INCLUDE WHEN CITING Published online May 5, 2017; DOI: 10.3171/2016.11.JNS161688. 


\section{Methods \\ Literature Search}

We searched Medline through PubMed, Embase, and the Cochrane Central Register of Controlled Trials in the Cochrane Library using the key words "moyamoya disease," "surgical treatment," "superficial temporal artery-middle cerebral artery (STA-MCA) anastomosis," "indirect bypass surgery," "combined surgery," "encephaloduroarteriosynangiosis (EDAS)," "encephaloduroarteriomyosynangiosis (EDAMS)," "conservative treatment," "STA-MCA bypass with EDAMS," "secondary stroke," "peri-operative complications," and "angiographic outcomes." 30 All papers published between January 1990 and May 2016 were included.

\section{Selection Criteria and Data Abstraction}

Our criteria for including papers in this study were: 1) adult MMD patients older than 16 years $;{ }^{27}$ 2) symptomatic patients who presented with ischemic or hemorrhagic insults, transient ischemic attack (TIA), or seizure; and 3) randomized controlled studies or prospective controlled or retrospective case-controlled studies that had a quality score greater than 5 on the Newcastle-Ottawa Scale (NOS) ${ }^{30,32}$ The exclusion criteria were: 1 ) incomplete data, 2) review articles or case reports, 3) study not written in English, and 4) secondary ICA stenosis or occlusion due to atherosclerosis, trauma, or radiation. ${ }^{30}$

Two authors (J.P.J. and J.E.K.) independently evaluated the eligibility of the studies and extracted the data using a standardized form. Disagreements between these 2 authors were resolved by discussion and consultation with a third author (C.W.O.). The primary end point was future strokes, including hemorrhagic and ischemic events, after intervention during the follow-up intervals. The secondary end points included perioperative complications and angiographic outcomes. Perioperative complications included hemorrhage or ischemic insults, seizure, hyperperfusion syndrome, wound problems, permanent neurological deficits, and death within 30 days after the procedure. ${ }^{17,30}$ For surgical methods, patients who underwent direct or combined revascularization were defined as the direct bypass group. Angiographic outcomes after revascularization were classified into 2 groups - good (angiographic opacification over one-third of MCA territory) and poor (under one-third) - based on the previous literature. ${ }^{25}$ This study was approved by the institutional review board of Seoul National University Hospital. This meta-analysis was performed according to the PRISMA guidelines.

\section{Statistical Analysis}

Mantel-Haenszel odds ratios (ORs) and 95\% confidence intervals (CIs) are presented for dichotomous variables. Heterogeneity was evaluated by using the $\mathrm{I}^{2}$ test. If $\mathrm{I}^{2}$ was less than $50 \%$, a fixed-effects model was used..$^{30}$ Publication bias was determined using Begg's funnel plot, Egger's test of the intercept, and the Begg and Mazumdar rank correlation test. ${ }^{1,3,7}$ Comprehensive meta-analysis software (CMA v2.2.064; Biostat) was used for all the above, with statistical significance indicated at $\mathrm{p}<0.05$.

\section{Results \\ Identification of Relevant Studies}

Figure 1 displays a flow diagram of the detailed search process. After record screening and determination of eligibility, 11 articles were included (Table 1 and Supplemental Table 1). Among the 11 studies, 6 compared future stroke events in adult MMD patients between surgical and conservative treatment, , $11,19,23,27,29$ and the remaining 5 investigated the difference in future stroke events between adult MMD patients who underwent direct bypass surgery and those who underwent indirect bypass surgery. ${ }^{2,12,16,23,28}$

\section{Efficacy of Bypass Surgery in Preventing Future Strokes in Adult MMD}

A total of 771 patients from 6 studies were included in this analysis (Fig. 2A). Among them, 531 patients underwent 586 bypass procedures and 240 received conservative treatment. Overall, bypass surgery significantly decreased the risk of future stroke events compared with conservative treatments in adult patients with MMD (OR $0.301,95 \%$ CI $0.196-0.462, \mathrm{p}<0.001)$. For adults with hemorrhagic presentation, 18 stroke events were noted in the bypass group and 21 in the conservative treatment group; bypass surgery significantly lowered the risk of future stroke events (OR 0.319, 95\% CI 0.150-0.678, p = 0.003; Fig. 2B). For adults with ischemic presentation, 35 stroke events were noted in the bypass group and 24 in the conservative group; for these patients also, bypass surgery decreased the stroke events significantly compared with conservative treatment (OR 0.240, 95\% CI 0.059-0.987, $\mathrm{p}=0.048$; (Fig. 2C). In the publication bias analysis for comparison between surgical and conservative treatments, Egger's regression test showed an intercept of -0.80 (95\% $\mathrm{CI}-5.30$ to $3.70, \mathrm{t}=0.50$, df 4 , and 2-tailed $\mathrm{p}=0.65$ ). For the rank correlation test, Kendall's tau was 0 with 2-tailed $\mathrm{p}=1.00$. Accordingly, there was no evidence of publication bias in this comparison (Fig. 3).

\section{Comparison of Efficacy of Direct and Indirect Bypass in Adult MMD}

A total of 341 patients and 441 surgical procedures (271 direct bypass procedures and 170 indirect bypass procedures) from 5 studies were included in the analysis of efficacy with respect to lowering the risk of future stroke events. There were 21 stroke events in the direct bypass group, resulting in a rate of $7.7 \%$ calculated on the basis of procedures (21 per 271 procedures). In comparison, there were 28 stroke events in the indirect bypass group, resulting in a rate of $16.5 \%$ (28 per 170 procedures). Direct bypass was associated with a significantly lower risk of future stroke events (OR 0.494, 95\% CI 0.264-0.927, $\mathrm{p}=0.028$; Fig. 4A). A total of 221 patients and 299 surgical procedures (182 direct bypass procedures and 117 indirect bypass procedures) from 4 studies were included in the analysis of perioperative complications. There were 55 perioperative complications in the direct bypass group, resulting in a rate of $30.2 \%$ (55 per 182 procedures). In comparison, there were 22 perioperative complications in the indirect bypass group, resulting in a rate of $18.8 \%(22$ 


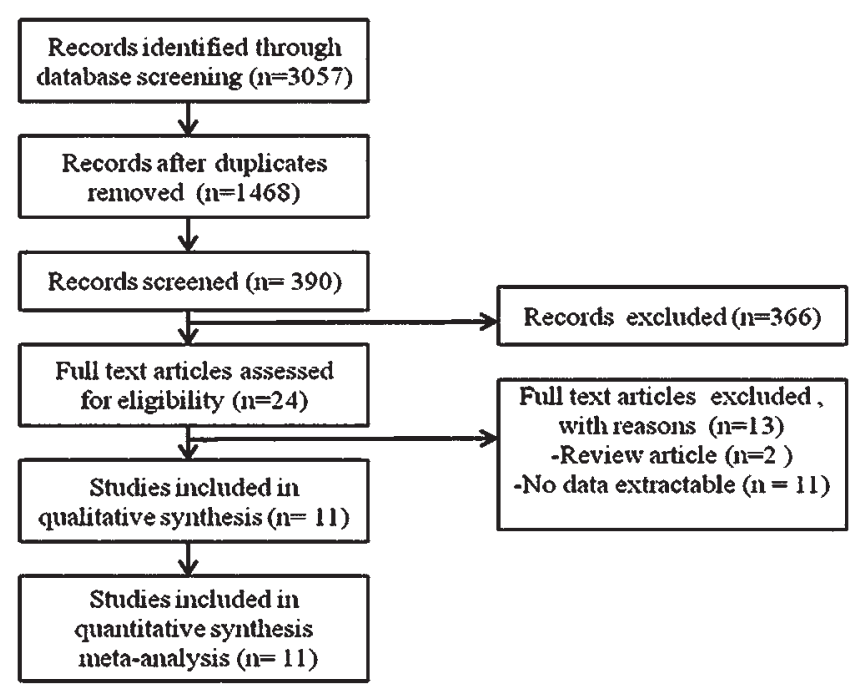

FIG. 1. Flow diagram for identification of relevant studies.

per 117 procedures). There was no significant difference between the 2 groups (OR 0.665 , 95\% CI $0.369-1.201$, p $=0.176$; Fig. 4B). A total of 218 patients with 267 surgical procedures (144 direct bypass procedures and 123 indirect bypass procedures) from 3 studies were included in the analysis of angiographic outcomes. After surgical revascularization, there were 129 good angiographic outcomes in the direct bypass group, resulting in a rate of $89.6 \%$ (129 per 144 procedures). In comparison, there were 65 good angiographic outcomes in the indirect bypass group, resulting in a rate of $52.8 \%$ (65 per 123 procedures). Good angiographic outcomes were more pronounced in patients who underwent direct bypass (OR 6.832, 95\% CI 3.51213.287, p < 0.001; Fig. 4C). In the publication bias analysis for future stroke events according to surgical procedures, Egger's regression test showed an intercept of $0.20(95 \%$ $\mathrm{CI},-4.50$ to $4.89, \mathrm{t}=0.13$, df 3 , and 2-tailed $\mathrm{p}=0.90$ ). For the rank correlation test, Kendall's tau was 0.10 with 2-tailed $\mathrm{p}=0.81$. Accordingly, there was no evidence of publication bias in this comparison (Fig. 5).

\section{Discussion}

In light of the differences in brain plasticity, clinical characteristics, and treatment outcomes between adult and pediatric patients with MMD, ${ }^{14,22,24}$ a previous systemic review ${ }^{15}$ and meta-analysis ${ }^{30}$ could not fully reflect treatment outcomes in adult MMD. Up to $40 \%$ of adult MMD patients presented with hemorrhage, with a reported disease progression rate of $17.4 \% .^{13,18,31}$ The postoperative stroke rate after combined bypass surgery has been found to be significantly higher in adult patients with MMD (7.9\% per surgery) than in pediatric patients with MMD (1.7\%). ${ }^{15}$ Our meta-analysis revealed that bypass surgery significantly decreases future stroke events compared with conservative treatments in adult MMD (OR 0.301, p < 0.001).

Miyamoto et al. ${ }^{27}$ compared surgical benefits of direct bypass to conservative treatment in adult MMD patients with hemorrhagic presentation in terms of primary end points (recurrent hemorrhage, completed stroke, or crescendo TIA) and secondary end points (recurrent hemorrhage, associated death, or severe morbidity). Kaplan-Meier survival analysis disclosed better outcomes for direct bypass with respect to primary and secondary end points (primary, 3.2\% per year for bypass vs $8.2 \%$ per year for conservative treatment, $\mathrm{p}=0.048$; and secondary, $2.7 \%$ per year vs $7.6 \%$ per year, respectively, $p=0.042$ ). Kim et al. ${ }^{19}$ investigated the efficacy of direct or combined bypass surgery for adult MMD patients with ischemic presentation. The annual stroke rates were $1.6 \%$ and $1.9 \%$ in the bypass and conservative treatment groups, respectively. The 10-year stroke rate was significantly lower in the bypass group than in the conservative treatment group $(9.4 \%$ vs $19.6 \%$, respectively, $\mathrm{p}=0.041$ ). Lee et al. ${ }^{23}$ evaluated recurrent stoke in symptomatic adult MMD patients according to clinical presentation and treatment modalities. For patients with hemorrhagic MMD, surgery in the form of mixed direct or indirect bypass was associated with a lower recurrent stroke rate than conservative treatment $(6$ [13.6\%] of 44 in the surgery group vs 4 [44.4\%] of 9 in the conservative group). For patients who also had ischemic presentation, the surgery group had a lower rate of recurrent stroke than the conservative treatment group (17

TABLE 1. Summary of clinical data from the studies included in this meta-analysis

\begin{tabular}{|c|c|c|c|c|c|}
\hline Authors \& Year & Country & Ethnicity (no. of pts) & Study Design & Treatment & NOS Score \\
\hline Hallemeier et al., 2006 & United States & Caucasian (23), African American (10), Asian (1) & Retrospective & Surgery, conservative & 6 \\
\hline Ohue et al., 2008 & Japan & Asian (17) & Retrospective & Surgery & 6 \\
\hline Han et al., 2011 & Canada & Caucasian (39) & Retrospective & Surgery & 6 \\
\hline Lee et al., 2012 & Korea & Asian (142) & Retrospective & Surgery, conservative & 6 \\
\hline Bang et al., 2012 & Korea & Asian (65) & Retrospective & Surgery & 8 \\
\hline Kim et al., 2012 & Korea & Asian (96) & Retrospective & Surgery & 8 \\
\hline Choi et al., 2012 & Korea & Asian (43) & Retrospective & Surgery & 7 \\
\hline Oyama et al., 2013 & Japan & Asian (30) & Retrospective & Surgery, conservative & 7 \\
\hline Choi et al., 2013 & Korea & Asian (44) & Retrospective & Surgery, conservative & 6 \\
\hline Miyamoto et al., 2014 & Japan & Asian (80) & Prospective & Surgery, conservative & 9 \\
\hline Kim et al., $2016^{19}$ & Korea & Asian (441) & Retrospective & Surgery, conservative & 7 \\
\hline
\end{tabular}

NOS $=$ Newcastle-Ottawa Scale; pts $=$ patients. 


\begin{tabular}{|c|c|c|c|c|c|c|c|}
\hline \multirow[t]{2}{*}{ Study mame } & \multicolumn{2}{|c|}{ Event / Total } & \multirow[b]{2}{*}{$\begin{array}{c}\text { MHodeds } \\
\text { rado }\end{array}$} & \multicolumn{3}{|c|}{ Stevisules for anch study } & \multirow[b]{2}{*}{ p-Value } \\
\hline & Conservalve & Surgery & & $\begin{array}{l}\text { Lawer } \\
\text { limit }\end{array}$ & $\begin{array}{l}\text { Uppor } \\
\text { limit }\end{array}$ & Z-Value & \\
\hline Hallemeire et al (2006) & $23 / 36$ & $3 / 20$ & 0.100 & 0.025 & 0.406 & 3.200 & \\
\hline Lee at al. (2012) & $10 / 18$ & $23 / 147$ & 0.148 & 0.053 & 0.416 & 3.628 & \\
\hline Oyama et al. (2013) & $5 / 37$ & $2 / 23$ & 0.610 & 0.108 & 3.437 & 0.561 & 0.5 \\
\hline Ohoi of al (2013) & $4 / 18$ & $6 / 53$ & 0.447 & 0.110 & 1.810 & -1.129 & \\
\hline Myamotoet al. (2014) & $13 / 38$ & $6 / 42$ & 0.321 & 0.107 & 0.957 & -2.030 & \\
\hline Kmel al. $(2016)^{99}$ & $18 / 140$ & $18 / 301$ & 0.431 & 0217 & 0.857 & -2.401 & \\
\hline & & & 0.301 & 0.196 & 0.462 & 5.481 & \\
\hline
\end{tabular}

Heterogeneity: $\mathrm{X}^{2}=6.198 . \mathrm{df}=5(\mathrm{p}=0.287): I^{2}=19.326 \%$

Test for overall effect: $Z=-5.481(p<0.001)$

study name

Lee et al. (2012)

Choi \& al. (2013)

Miyemoto a a. (2014)

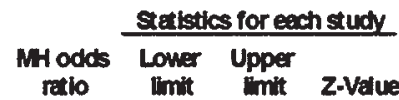

\section{Lover Upper}

$0.197 \quad 0.041$

$0.447 \quad 0.110$

$0.321 \quad 0.107$

0.319

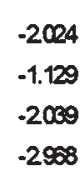

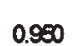

1.810

0.967

0.678

Heterogeneity: $\mathrm{X}^{2}=0.581 . \mathrm{df}=2(\mathrm{p}=0.748): I^{2}=0 \%$

Test for overall effect: $Z=-2.968(p=0.003)$

\begin{tabular}{|c|c|c|c|c|c|c|c|}
\hline \multirow[t]{2}{*}{ Study name } & \multicolumn{2}{|c|}{ Events / Tota } & \multirow[b]{2}{*}{$\begin{array}{l}\text { MH odds } \\
\text { ratio }\end{array}$} & \multicolumn{3}{|c|}{ Statistics for eech study } & \multirow[b]{2}{*}{ p-Value } \\
\hline & Conservative & surgery & & $\begin{array}{l}\text { Lover } \\
\text { limit }\end{array}$ & $\begin{array}{c}\text { Upper } \\
\text { limit }\end{array}$ & Z-Value & \\
\hline Lee et al. (2012) & $6 / 9$ & $17 / 103$ & 0.009 & 0.002 & 0.434 & -3.064 & 0.002 \\
\hline \multirow[t]{2}{*}{ Kimeta. $(2016)^{19}$} & $18 / 140$ & $18 / 301$ & 0.431 & 0.217 & 0.857 & -2401 & 0.016 \\
\hline & & & 0.240 & 0.069 & 0.987 & -1.978 & 0.048 \\
\hline
\end{tabular}

Heterogeneity: $\mathrm{X}^{2}=3.129, \mathrm{df}=1(\mathrm{p}=0.077) ; R^{2}=68.041^{\circ} \%$

Test for overall effect: $Z=-1.979(p=0.048)$

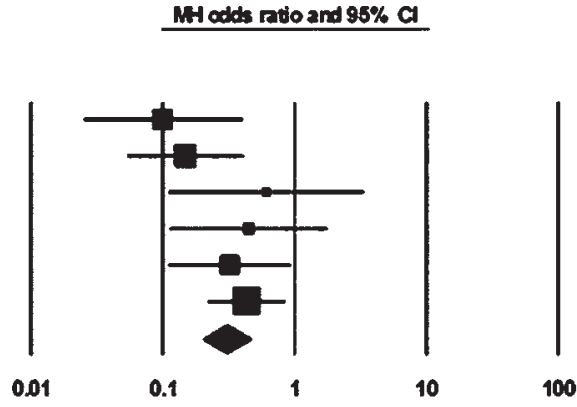

Surglcal nreatment Cousenvative treatnent MH odts ritlo and $9 \% \% \mathrm{Cl}$

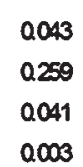

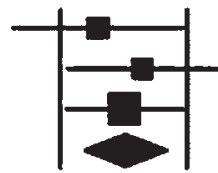

a1

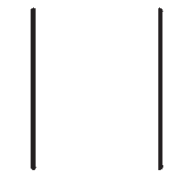

10100

Surgical neatment

Consenvathe treatineat MH odds ratio and $98 \% \mathrm{Cl}$

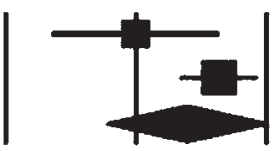

0.1

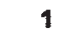

10

100

Surdical neatment

FIG. 2. Forest plots for future stroke events in all adult MMD patients included in the studies (A), future stroke events in MMD patients with hemorrhage presentation (B), and future stroke events in MMD patients with ischemic presentation (C). MH = Mantel-Haenszel.

[16.5\%] of 103 in the surgery group vs 6 [66.7\%] of 9 in the conservative treatment group). In contrast, Qian et al. ${ }^{30} \mathrm{did}$ not find a significant difference in recurrent stroke prevention between surgical and conservative treatment in MMD patients with an ischemic presentation (OR $0.45,95 \%$ CI $0.15-1.29, \mathrm{p}=0.14)$. However, their conclusion was based

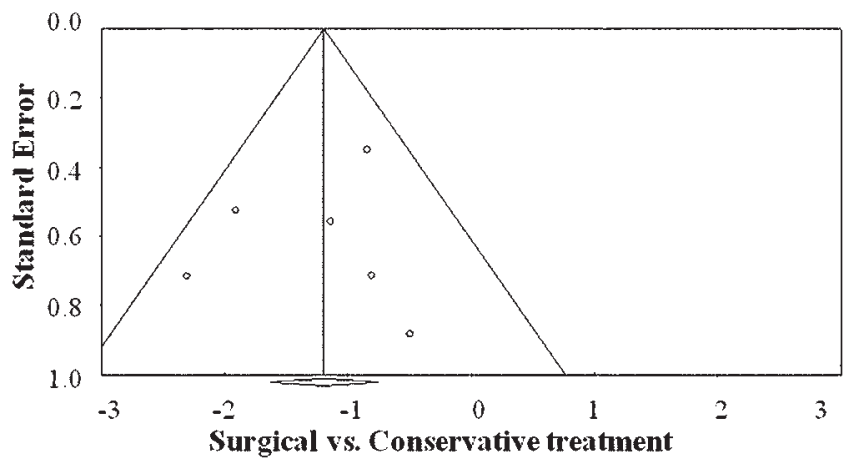

FIG. 3. Funnel plot for publication bias in future stroke events in total adult MMD patients. on a heterogeneous population with respect to age (including pediatric and adult MMD patients). Regarding adults, our meta-analysis revealed a benefit for surgery (in comparison with conservative treatment) with respect to future stroke prevention for patients with a hemorrhagic presentation (OR 0.319, $\mathrm{p}=0.003)$ and for those with an ischemic presentation (OR 0.240, $\mathrm{p}=0.048$ ).

The difference in surgical efficacy between the direct and indirect bypass techniques remains controversial in the treatment of symptomatic adult MMD, although treatment outcomes have been increasingly reported..$^{4,15}$ In a systematic review, Fung et al. ${ }^{8}$ found that there was no significant difference between these 2 techniques with respect to symptom improvement. A recent meta-analysis ${ }^{30}$ showed that indirect bypass had a lower efficacy with respect to prevention of recurrent stroke (OR 1.79,95\% CI 1.14-2.82, $\mathrm{p}=0.01)$ in a mixed adult and pediatric population. Direct bypass is a technically challenging and time-consuming procedure. Accordingly, it is thought to entail a higher risk of complications than indirect bypass. Cho et al. ${ }^{4}$ reported that combined bypass surgery was associated with a $0.4 \%$ annual symptomatic postoperative hemorrhage rate and 


\begin{tabular}{|c|c|c|c|c|c|c|c|}
\hline \multirow[t]{2}{*}{ Study name } & \multicolumn{2}{|c|}{ Events / Total } & \multicolumn{5}{|c|}{ Statistice for each study } \\
\hline & Indirect & Direct & $\begin{array}{l}\text { MH odds } \\
\text { ratio }\end{array}$ & $\begin{array}{l}\text { Lower } \\
\text { limit }\end{array}$ & $\begin{array}{l}\text { Upper } \\
\text { limit }\end{array}$ & Z-Value & p-Value \\
\hline Ohuedta. (2008) & $1 / 8$ & $3 / 24$ & 1.000 & 0.009 & 11.220 & 0.000 & 1.000 \\
\hline Hanet a. (2011) & $0 / 8$ & $4 / 46$ & 1.800 & 0.068 & 36.631 & 0.382 & 0.70 \\
\hline Bang et a. (2012) & $2 / 14$ & $1 / 60$ & $0.1 C e$ & 0.000 & 1214 & -1807 & 0.071 \\
\hline Kim eda. (2012) & $7 / 62$ & $8 / 72$ & 0988 & 0.336 & 2882 & -0.033 & 0.974 \\
\hline Leeda. (2012) & $18 / 78$ & $5 / \omega$ & 0260 & 0.091 & 0.745 & -2508 & 0.012 \\
\hline & & & 0.494 & 0.264 & 0.927 & -2197 & 0. \\
\hline
\end{tabular}

Heterogeneity: $\mathrm{X}^{2}=5.584 . \mathrm{df}=4(\mathrm{p}=0.232): R^{2}=28.371 \%$

Test for overall effect: $Z=-2.197(p=0.028)$

\begin{tabular}{|c|c|c|c|c|c|c|c|}
\hline \multirow[t]{2}{*}{ Study name } & \multicolumn{2}{|c|}{ Events / Total } & \multicolumn{5}{|c|}{ Statistics for each study } \\
\hline & Difrect & Indirect & $\begin{array}{c}\text { MH } \\
\text { odds ratio }\end{array}$ & $\begin{array}{l}\text { Lower } \\
\text { limit }\end{array}$ & $\begin{array}{l}\text { Upper } \\
\text { limit }\end{array}$ & ZValue & p-Val \\
\hline Ohue et al .(2008) & $8 / 24$ & $1 / 8$ & 0286 & 0.030 & 2.740 & -1.086 & \\
\hline Beng et al. (2012) & $23 / 61$ & $5 / 14$ & 0918 & 0274 & 3.077 & -0.139 & \\
\hline Kim et al. (2012) & $20 / 72$ & $14 / 62$ & 0.758 & 0345 & 1.667 & -0.688 & \\
\hline Choi et al. (2012) & $4 / 25$ & $2 / 33$ & 0339 & 0.057 & 2.020 & -1.188 & \\
\hline & & & 0.665 & 0369 & 1201 & -1.352 & \\
\hline
\end{tabular}

Heterogeneity: $\mathrm{X}^{2}=1.464, \mathrm{df}=3(\mathrm{p}=0.691) ; I^{2}=0 \%$

Test for overall effect: $Z=-1.352(p=0.176)$

\begin{tabular}{|c|c|c|c|c|c|c|c|}
\hline \multirow[t]{2}{*}{ Study name } & \multicolumn{2}{|c|}{ Good / Total } & \multicolumn{5}{|c|}{ Statistics for each study } \\
\hline & Indirec & Direct & $\begin{array}{l}\text { MH odds } \\
\text { ratio }\end{array}$ & $\begin{array}{l}\text { Lower } \\
\text { limit }\end{array}$ & $\begin{array}{l}\text { Upper } \\
\text { limit }\end{array}$ & Z-Value & - Value \\
\hline Bang et al. (2012) & $5 / 13$ & $56 / 58$ & 29.333 & 5.851 & 147.056 & 4.108 & 0.000 \\
\hline Leetal. (2012) & $36 / \pi$ & $51 / 61$ & 5.808 & 2578 & 13.087 & 4.245 & 0.000 \\
\hline Cha et al. (2012) & $24 / 33$ & $23 / 25$ & 4.313 & 0.840 & 22130 & 1.752 & 0.080 \\
\hline & & & 6.832 & 3.512 & 13.287 & 5.651 & 0.000 \\
\hline
\end{tabular}

Heterogeneity: $\mathrm{X}^{2}=3.596, \mathrm{df}=2(\mathrm{p}=0.166) ; r^{2}=44.381 \%$

Test for overall effect: $Z=5.661(p<0.001)$

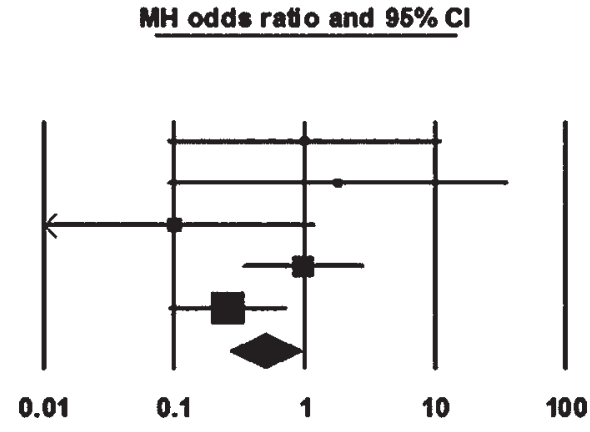

Direct Surgery Indirect Surgery

MH odds ratio and $95 \% \mathrm{CI}$
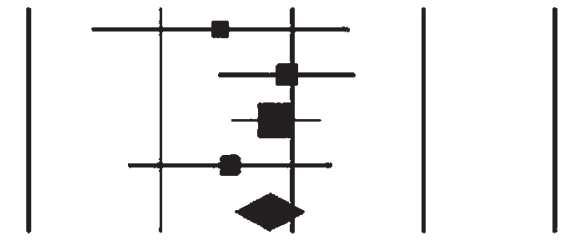

0.01

0.1

1

10

100

\section{Indirect Surgery Direct Surgery}

MH odds ratio and $95 \% \mathrm{CI}$
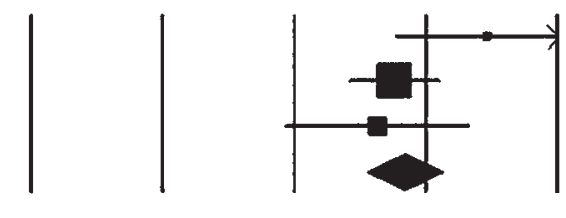

\begin{tabular}{ccccc}
0.01 & 0.1 & 1 & 10 & 100 \\
& Indirect Surgery & \multicolumn{2}{c}{ Direct Surgery } &
\end{tabular}

FIG. 4. Forest plots for analyses of future stroke events according to surgical procedures (A), perioperative complications according to surgical procedures (B), and good angiographic outcomes according to surgical procedures (C).

a $0.2 \%$ annual postoperative infarction rate in adults. A systematic review showed that the difference between the 2 surgical techniques with respect to postoperative stroke rate did not reach significance $(7.6 \%$ for direct or combined bypass vs $5.1 \%$ for indirect bypass). ${ }^{15}$ In the study, postoperative stroke was defined as cerebral infarction, intracerebral hemorrhage, subarachnoid hemorrhage, or intraventricular hemorrhage that developed during or within 4 weeks after the procedure. Sun et al. ${ }^{33}$ evaluated surgical efficacy of direct, indirect, and combined bypass in adult MMD. They concluded that direct bypass provides better prevention of long-term ischemia than indirect bypass (OR $0.51,95 \%$ CI $0.33-0.77$ ) or combined bypass (OR 0.47, 95\% CI 0.31-0.72). Regarding treatment outcomes, direct or combined bypass showed better long-term favorable outcomes than indirect bypass. However, the authors analyzed treatment outcomes irrespective of MMD symp-

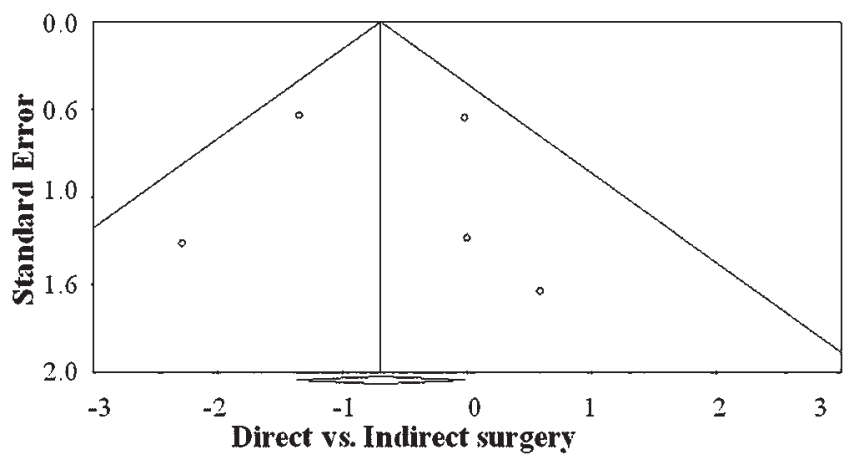

FIG. 5. Funnel plot for publication bias in future stroke events according to surgical procedures in adult MMD patients. 
toms. In this meta-analysis, we investigated complications, including ischemic or hemorrhagic insults, seizure, hyperperfusion syndrome, wound problems, and perioperative death in symptomatic MMD patients..$^{30}$ Perioperative complications were noted more frequently in the direct bypass group (55 [30.2\%] of 182 cases) than in the indirect bypass group (22 [18.8\%] of 117 cases, $p=0.176)$, although the difference did not reach statistical significance. One reason for the lack of statistical significance may be the relatively high complication rate in the indirect bypass group reported by Kim et al. ${ }^{16}$ Nevertheless, the results of our metaanalysis must be interpreted with caution, particularly due to the small number of studies that we were able to include.

Compared with indirect bypass, direct bypass yields good revascularization..$^{5,15}$ Kazumata et al..$^{15}$ reported that excellent revascularization on postoperative angiography (angiographic opacification over two-thirds of MCA territory) was more pronounced after direct bypass $(57.5 \%$ in direct bypass vs $29.4 \%$ in indirect bypass, $\mathrm{p}<0.05$ ). For combined bypass surgery, the relative revascularization area $(\mathrm{RA})$, defined as (RA/supratentorial area) $\times 100$, increased from $44.2 \%$ in the short-term period (approximately 6 months) to $54.8 \%$ in the long-term period (approximately 5 years). ${ }^{4}$ In the present meta-analysis, good angiographic outcomes were noted more often after direct bypass (129 [89.6\%] of 144 cases) than after indirect bypass $(65$ [52.8\%] of 123 cases, $p<0.001)$.

Recently, several systematic reviews and meta-analyses of treatment outcomes in MMD patients have been reported. ${ }^{15,17,30,33}$ Qian et al..$^{30}$ evaluated the efficacy of surgery in preventing secondary strokes in symptomatic MMD patients. They reported that bypass surgery significantly reduced the risk of secondary stroke (OR 0.17, p < 0.01) compared with conservative treatment. According to Kazumata et al.,15 the postoperative stroke rate for direct/ combined bypass surgery was comparable to that for indirect bypass surgery. However, the results of these 2 studies $^{15,30}$ were derived from a heterogeneous population of adult and pediatric MMD patients. Due to the differences in clinical manifestations and surgical preferences according to age, surgical treatment outcomes could be better defined in a homogeneous population. Pediatric MMD mainly presents with ischemic symptoms. In contrast, adults with MMD experience more hemorrhagic events. ${ }^{20}$ In addition, the benefit of direct bypass has been increasingly reported. .19 $^{19}$ Accordingly, we included only symptomatic adult MMD patients in our assessment of treatment outcomes in the present meta-analysis. Sun et al. ${ }^{33}$ reported perioperative complications and long-term outcomes for adult MMD patients who underwent bypass surgery. However, these authors included the results obtained by Mesiwala et al. ${ }^{26}$ in their analysis. The mean age of Mesiwala and colleagues' patients $(n=39)$ at diagnosis was 34 years (range 10-55 years). Moreover, we could not confirm the exact number of events. Therefore, the results obtained by Mesiwala et al. were excluded from our analysis. Kim et al. ${ }^{17}$ reported a meta-analysis of bypass surgery in adult MMD patients. They concluded that direct or combined bypass provides better angiographic revascularization in adult MMD patients with symptomatic or hemodynamic instability. However, they reached this conclusion based on analysis that included patients with moyamoya syndrome and asymptomatic MMD patients. ${ }^{9}$ In addition, stroke timing was not fully described. Compared with the study by Kim et al., ${ }^{17}$ we provided detailed information on future stroke events according to the patients' presentation. Moreover, we included studies that were published more recently ${ }^{19,27}$ Accordingly, the results of our study appear to differ from those of previous meta-analyses.

\section{Study Limitations}

There are some limitations in this investigation. First, all but one of the studies included in this analysis were retrospective. Second, 9 of the 11 studies were conducted in Asia, and rates of hemorrhagic presentation are likely to differ by region, as shown by Kleinloog et al..$^{20}$ who reported regional differences in hemorrhage presentation rates in MMD patients (China, 56\%; Japan, 21\%; and Hawaii, 29\%). Third, inter-institutional differences, such as diagnostic steps, surgical techniques, and preferences, could be limitations to a definitive conclusion. In this study, we only included studies with a quality score greater than 5 on the NOS (Supplemental Table 1). In addition, there was no evidence of publication bias. Nevertheless, the results of the meta-analysis should be interpreted with caution due to the level of heterogeneity and the fact that only 1 of the 11 studies included was prospective. Randomized controlled studies including more detailed data on repetitive stroke and perioperative complications according to treatment modalities and homogeneous diagnostic decision in adult MMD will be required.

\section{Conclusions}

Bypass surgery can be effective in preventing future stroke in adult patients with MMD. Direct bypass seems to provide better risk reduction of stroke than indirect bypass in these patients. Randomized, controlled, multicenter studies are needed to elucidate treatment outcomes in adult MMD.

\section{Acknowledgments}

We would like to thank Sung-Eun Kim for her help with the data collection and statistical support.

\section{References}

1. Bang CS, Baik GH, Shin IS, Kim JB, Suk KT, Yoon JH, et al: Effect of intragastric injection of botulinum toxin A for the treatment of obesity: a meta-analysis and meta-regression. Gastrointest Endosc 81:1141-1149, 1149.e1-1149.e7, 2015

2. Bang JS, Kwon OK, Kim JE, Kang HS, Park H, Cho SY, et al: Quantitative angiographic comparison with the OSIRIS program between the direct and indirect revascularization modalities in adult moyamoya disease. Neurosurgery 70:625-633, 2012

3. Begg CB, Mazumdar M: Operating characteristics of a rank correlation test for publication bias. Biometrics 50:10881101, 1994

4. Cho WS, Kim JE, Kim CH, Ban SP, Kang HS, Son YJ, et al: Long-term outcomes after combined revascularization surgery in adult moyamoya disease. Stroke 45:3025-3031, 2014

5. Choi IJ, Cho SJ, Chang JC, Park SQ, Park HK: Angiographic results of indirect and combined bypass surgery for adult 
moyamoya disease. J Cerebrovasc Endovasc Neurosurg 14:216-222, 2012

6. Choi WS, Lee SB, Kim DS, Huh PW, Yoo DS, Lee TG, et al: Thirteen-year experience of 44 patients with adult hemorrhagic moyamoya disease from a single institution: clinical analysis by management modality. J Cerebrovasc Endovasc Neurosurg 15:191-199, 2013

7. Egger M, Davey Smith G, Schneider M, Minder C: Bias in meta-analysis detected by a simple, graphical test. BMJ 315:629-634, 1997

8. Fung LW, Thompson D, Ganesan V: Revascularisation surgery for paediatric moyamoya: a review of the literature. Childs Nerv Syst 21:358-364, 2005

9. Gross BA, Du R: Adult moyamoya after revascularization. Acta Neurochir (Wien) 155:247-254, 2013

10. Gross BA, Du R: The natural history of moyamoya in a North American adult cohort. J Clin Neurosci 20:44-48, 2013

11. Hallemeier CL, Rich KM, Grubb RL Jr, Chicoine MR, Moran CJ, Cross DT III, et al: Clinical features and outcome in North American adults with moyamoya phenomenon. Stroke 37:1490-1496, 2006

12. Han JS, Abou-Hamden A, Mandell DM, Poublanc J, Crawley AP, Fisher JA, et al: Impact of extracranial-intracranial bypass on cerebrovascular reactivity and clinical outcome in patients with symptomatic moyamoya vasculopathy. Stroke 42:3047-3054, 2011

13. Jeon JP, Yun T, Jin X, Cho WS, Son YJ, Bang JS, et al: ${ }^{1} \mathrm{H}-$ NMR-based metabolomic analysis of cerebrospinal fluid from adult bilateral moyamoya disease: comparison with unilateral moyamoya disease and atherosclerotic stenosis. Medicine (Baltimore) 94:e629, 2015

14. Jeon JS, Ahn JH, Moon YJ, Cho WS, Son YJ, Kim SK, et al: Expression of cellular retinoic acid-binding protein-I (CRABP-I) in the cerebrospinal fluid of adult onset moyamoya disease and its association with clinical presentation and postoperative haemodynamic change. J Neurol Neurosurg Psychiatry 85:726-731, 2014

15. Kazumata K, Ito M, Tokairin K, Ito Y, Houkin K, Nakayama $\mathrm{N}$, et al: The frequency of postoperative stroke in moyamoya disease following combined revascularization: a single-university series and systematic review. J Neurosurg 121:432440, 2014

16. Kim DS, Huh PW, Kim HS, Kim IS, Choi S, Mok JH, et al: Surgical treatment of moyamoya disease in adults: combined direct and indirect vs. indirect bypass surgery. Neurol Med Chir (Tokyo) 52:333-338, 2012

17. Kim H, Jang DK, Han YM, Sung JH, Park IS, Lee KS, et al: Direct bypass versus indirect bypass in adult moyamoya angiopathy with symptoms or hemodynamic instability: a meta-analysis of comparative studies. World Neurosurg 94:273-284, 2016

18. Kim JE, Jeon JS: An update on the diagnosis and treatment of adult moyamoya disease taking into consideration controversial issues. Neurol Res 36:407-416, 2014

19. Kim T, Oh CW, Kwon OK, Hwang G, Kim JE, Kang HS, et al: Stroke prevention by direct revascularization for patients with adult-onset moyamoya disease presenting with ischemia. J Neurosurg 124:1788-1793, 2016 (Erratum in J Neurosurg 124:1875, 2016)

20. Kleinloog R, Regli L, Rinkel GJ, Klijn CJ: Regional differences in incidence and patient characteristics of moyamoya disease: a systematic review. J Neurol Neurosurg Psychiatry 83:531-536, 2012

21. Kraemer M, Heienbrok W, Berlit P: Moyamoya disease in Europeans. Stroke 39:3193-3200, 2008

22. Kuroda S, Ishikawa T, Houkin K, Nanba R, Hokari M, Iwasaki Y: Incidence and clinical features of disease progression in adult moyamoya disease. Stroke 36:2148-2153, 2005

23. Lee SB, Kim DS, Huh PW, Yoo DS, Lee TG, Cho KS: Long- term follow-up results in 142 adult patients with moyamoya disease according to management modality. Acta Neurochir (Wien) 154:1179-1187, 2012

24. Lee SC, Jeon JS, Kim JE, Chung YS, Ahn JH, Cho WS, et al: Contralateral progression and its risk factor in surgically treated unilateral adult moyamoya disease with a review of pertinent literature. Acta Neurochir (Wien) 156:103-111, 2014

25. Matsushima T, Inoue T, Suzuki SO, Fujii K, Fukui M, Hasuo $\mathrm{K}$ : Surgical treatment of moyamoya disease in pediatric patients-comparison between the results of indirect and direct revascularization procedures. Neurosurgery 31:401-405, 1992

26. Mesiwala AH, Sviri G, Fatemi N, Britz GW, Newell DW: Long-term outcome of superficial temporal artery-middle cerebral artery bypass for patients with moyamoya disease in the US. Neurosurg Focus 24(2):E15, 2008

27. Miyamoto S, Yoshimoto T, Hashimoto N, Okada Y, Tsuji I, Tominaga T, et al: Effects of extracranial-intracranial bypass for patients with hemorrhagic moyamoya disease: results of the Japan Adult Moyamoya Trial. Stroke 45:1415-1421, 2014

28. Ohue S, Kumon Y, Kohno K, Watanabe H, Iwata S, Ohnishi $\mathrm{T}$ : Postoperative temporary neurological deficits in adults with moyamoya disease. Surg Neurol 69:281-287, 2008

29. Oyama H, Kito A, Maki H, Hattori K, Noda T, Wada K: Cerebral hemorrhage and cerebral infarction in 30 cases of adult moyamoya disease: comparison between conservative therapy and superficial temporal artery-middle cerebral artery anastomosis. Nagoya J Med Sci 75:37-40, 2013

30. Qian C, Yu X, Li J, Chen J, Wang L, Chen G: The efficacy of surgical treatment for the secondary prevention of stroke in symptomatic moyamoya disease: a meta-analysis. Medicine (Baltimore) 94:e2218, 2015

31. Scott RM, Smith ER: Moyamoya disease and moyamoya syndrome. N Engl J Med 360:1226-1237, 2009

32. Stang A: Critical evaluation of the Newcastle-Ottawa scale for the assessment of the quality of nonrandomized studies in meta-analyses. Eur J Epidemiol 25:603-605, 2010

33. Sun H, Wilson C, Ozpinar A, Safavi-Abbasi S, Zhao Y, Nakaji $\mathrm{P}$, et al: Perioperative complications and long-term outcomes after bypasses in adults with moyamoya disease: a systematic review and meta-analysis. World Neurosurg 92:179-188, 2016

34. Suzuki J, Takaku A: Cerebrovascular "moyamoya" disease. Disease showing abnormal net-like vessels in base of brain. Arch Neurol 20:288-299, 1969

\section{Disclosures}

This study was supported by BioGreen 21 (PJ01121401) of the Rural Development Administration.

\section{Author Contributions}

Conception and design: Kim. Acquisition of data: Jeon, Cho. Analysis and interpretation of data: Jeon, Son. Critically revising the article: Oh. Reviewed submitted version of manuscript: Bang.

\section{Supplemental Information}

\section{Online-Only Content}

Supplemental material is available with the online version of the article.

Supplemental Table. https://thejns.org/doi/suppl/10.3171/2016. 11.JNS161688.

\section{Correspondence}

Jeong Eun Kim, Department of Neurosurgery, Seoul National University College of Medicine, Seoul National University Hospital, 101 Daehak-ro, Jongno-gu, Seoul 110-744, Korea. email: eunkim@snu.ac.kr. 